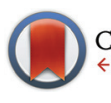

CrossMark $\leftarrow$ click for updates

Cite this: Polym. Chem., 2015, 6, 2769

Received 26th January 2015,

Accepted 13th February 2015

DOI: 10.1039/c5py00109a

www.rsc.org/polymers

\title{
Thermophilic films and fibers from photo cross-linkable UCST-type polymers $\uparrow$
}

\author{
Fangyao Liu, ${ }^{a}$ Shaohua Jiang, ${ }^{a}$ Leonid Ionov ${ }^{b}$ and Seema Agarwal*a
}

Photo cross-linkable thermoresponsive polymers of UCST-type based on acrylamide (AAm) and acrylonitrile (AN) useful for preparing thermophilic hydrogel films and fibers are presented. The polymers prepared via free radical and reversible addition fragmentation chain-transfer (RAFT) polymerization methods using $\mathrm{N}$-(4-benzoylphenyl)acrylamide (BPAm) as photo cross-linkable comonomers provided highly stable UCST-type phase transition in water reproducible without hysteresis for many cycles. The cloud point could be manipulated by varying the acrylonitrile amount in the feed. Chemically cross-linked hydrogel films and nanofibers (average diameter $500 \mathrm{~nm}$ ) were successfully prepared from the ter-copolymers by solution casting and electrospinning followed by UV irradiation. These hydrogels showed a continuous positive volume transition behavior in water with increasing temperature that was utilized for the design of microactuators.

\section{Introduction}

Smart polymers are able to change their properties markedly in response to a minor change of environment, for example, magnetic field, $\mathrm{pH}$, temperature, light, salt concentration etc. Among them, thermoresponsive polymers attract more and more attention because the temperature can be easily manipulated and the corresponding polymers are extensively applied in biological and medical areas. ${ }^{1-4}$ There are two types of thermoresponsive polymers based on the type of phase transition in water. The most widely studied thermoresponsive polymers are of the type showing a lower critical solution temperature (LCST); one of the common examples is poly( $N$-isopropylacrylamide) (PNIPAM). Such polymers are soluble in water at low temperature and precipitated from the solution upon heating above a critical temperature called the cloud point. The corresponding cross-linked polymers are well-studied as thermophobic hydrogels which show a negative volume-phase transition with shrinkage above the critical temperature. ${ }^{5,6}$ The other type of thermoresponsive polymer shows an upper critical solution temperature (UCST), i.e. it is soluble in water only above the critical temperature. ${ }^{7,8}$ The cross-linked UCST-type

\footnotetext{
${ }^{a}$ University of Bayreuth, Macromolecular Chemistry II and Bayreuth Center for Colloids and Interfaces, Universitätstrasse 30, D-95440 Bayreuth, Germany. E-mail: agarwal@uni-bayreuth.de; Fax: +49-921-553393; Tel: +49-921-553397 ${ }^{b}$ Leibniz Institute of Polymer Research Dresden, Hohe Str. 6, D-01069 Dresden, Germany

$\dagger$ Electronic supplementary information (ESI) available: ${ }^{1} \mathrm{H}-\mathrm{NMR}$ of synthesized RAFT poly(AAm-AN-BPA), UV/Vis spectroscopy of RAFT poly(AAm-AN-BPA), as well as turbidity measurements of 0.1 wt $\%$ solution of poly(AAm-AN-BPAm) made by FRP using V-70 as an initiator. See DOI: 10.1039/c5py00109a
}

polymers show a positive volume-phase transition (thermophilic hydrogels). ${ }^{9}$ Examples of thermophilic hydrogels are only a few and mostly based on temperature dependent ionic or hydrogen-bonding interactions in the macromolecular chains. ${ }^{10}$ Examples of ionic thermophilic hydrogels are based on cross-linked zwitterionic polysulfobetaines. ${ }^{11,12}$ The most studied example of non-ionic thermophilic hydrogels was the interpenetrating polymer networks (IPNs) of acrylamide (AAm) and acrylic acid (AAc). ${ }^{13,14}$ Recently two more examples of nonionic thermoresponsive hydrogels were shown. In one of the studies, Shimada et al. provided thermophilic hydrogels based on cross-linked poly(allylurea-co-allylamine) copolymers. ${ }^{15}$ Poly (allylurea) based copolymers were already known to show UCST-type phase transition under physiological $\mathrm{pH}$ and salt conditions. ${ }^{16,17}$ In our recent results, we also showed thermophilic behavior of non-ionic chemically cross-linked poly $(N$ acryloylglycinamide) poly(NAGA) with $N, N^{\prime}$-methylenebis(acrylamide) (MBAAm) in pure water and electrolyte solutions. ${ }^{9}$ Homopolymers of NAGA as well as copolymers of AAm and acrylonitrile (AN) prepared via free radical polymerization using azobisisobutyronitrile (AIBN) as a non-ionic initiator were shown to be thermoresponsive polymers of UCST-type in our previous studies. ${ }^{18,19}$

In this work we present photo cross-linkable thermoresponsive polymers of UCST-type based on copolymers of AAm and AN. The effect of the polymerization type, cross-linker structure and concentration on thermoresponsive behavior and reproducibility of thermoresponsive transitions was studied. The polymers were processed in the form of films by solution casting and nanofibers by electrospinning and subsequently cross-linked by UV light. The cross-linked films and fibers 
showed thermophilic hydrogel behavior with reversible swelling with change in temperature. The photo cross-linked UCST-polymer-poly(methyl methacrylate) bilayers showed thermoresponsive self-rolling behavior interesting for use in microactuators.

\section{Experimental part}

\section{Materials}

Acrylamide (AAm, electrophoresis grade, $\geq 99 \%$, Sigma), acrylonitrile (AN, 99+\%, Acros Organics), cyanomethyl dodecyl trithiocarbonate (CMDT, 98\%, Aldrich) and 2,2'-azobis(4methoxy-2,4-dimethyl valeronitrile) (V-70, 96\%, Wako) were used as received. Azobisisobutyronitrile (AIBN, 98\%, Fluka) was recrystallized from ethanol. 4-Acryloyloxybenzophenone (BPA) was synthesized according to the literature. ${ }^{20} \mathrm{~N}$-(4-Benzoylphenyl)acrylamide (BPAm) was prepared as described in the literature. ${ }^{21}$ All solvents were distilled before use. Water was obtained from a MilliQ Plus (Millipore) apparatus.

\section{Analytical techniques}

Thermoresponsivity was studied by measuring relative transmittance as a function of temperature (turbidity measurement) using a TP1-D Tepper turbidity photometer (wavelength $670 \mathrm{~nm}$, cell path length $10 \mathrm{~mm}$ ) while stirring the solution. For turbidity measurements the samples were cooled from $60{ }^{\circ} \mathrm{C}$ to $3.5^{\circ} \mathrm{C}$ at a constant rate of $1.0^{\circ} \mathrm{C} \mathrm{min}^{-1}$ followed by reheating to the starting temperature with the same rate. The inflection point of the transmittance curve was considered as the cloud point. It was graphically determined by the maximum of the first derivative of the heating or the cooling curve, respectively. Fiber mat transmittance measurements were performed on a JASCO V-630 UV/Vis-Spectrophotometer with ETCS-761, a water-cooled Peltier thermostatted cell holder with a stirrer. The wavelength was $670 \mathrm{~nm}$. UV treatment was performed on UVAHAND $250 \mathrm{GS}$, a high-intensity ultra-violet lamp. The UV radiation spectra emitted by the UV lamp were between 320 and $390 \mathrm{~nm}$ (wavelength). The respective radi-

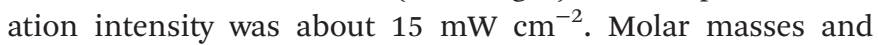
molar mass distributions of the polymers were determined by gel permeation chromatography (GPC) using dimethyl sulfoxide as the eluent. Two PSS PolarSil linear S columns (particle size $5 \mu \mathrm{m}$, dimension $8 \mathrm{~mm} \times 300 \mathrm{~mm}$ ) calibrated using narrow pullulan standards and a differential refractive index detector were employed. The flow rate was $0.7 \mathrm{~mL} \mathrm{~min}^{-1}$. The molar mass distributions were calculated using the software WinGPC Unity.

A scanning electron microscope (SEM, Zeiss LEO 1530, EHT $=3 \mathrm{kV}$ ) was used to observe the surface morphology. The fiber diameter was measured by using Image J software. The average fiber diameter was determined statistically by measuring 100 fibers from 5 SEM photos. The samples for SEM were sputter-coated with platinum of $3.0 \mathrm{~nm}$ prior to scanning. The thickness and the area of the mat were observed and measured using an optical microscope (VHX 2000).

\section{General polymerization procedure}

In a typical polymerization, $5.112 \mathrm{~g}$ AAm (90 eq.), $419 \mu \mathrm{L} \mathrm{AN} \mathrm{(8} \mathrm{eq.)}$ and $402 \mathrm{mg}$ BPAm (2 eq.) were dissolved in $70 \mathrm{~mL}$ distilled DMSO in a $250 \mathrm{~mL}$ Schlenk flask. It was degassed using three freeze-pump-thaw cycles. Under nitrogen gas, $37 \mathrm{mg} \mathrm{V-70}$ ( 0.15 eq.) was added to the reaction mixture. The mixture was placed in a preheated oil bath and stirred for $5.5 \mathrm{~h}$ at $45^{\circ} \mathrm{C}$. The reaction was stopped by cooling in liquid nitrogen and air contact. The polymers were precipitated from $800 \mathrm{~mL}$ methanol. It was filtered and washed with methanol. Subsequently it was dried in the vacuum oven at $70{ }^{\circ} \mathrm{C}$ for $24 \mathrm{~h}$ to obtain a powdery white polymer.

${ }^{1} \mathrm{H}$ NMR $\left(300 \mathrm{MHz}, \delta / \mathrm{ppm}\right.$, DMSO- $d_{6}$, the DMSO peak was calibrated to $\delta=2.50 \mathrm{ppm}$ ) 1.1-1.8 (polymer backbone, $-\mathrm{CH}_{2}-$ ), 1.9-2.3 (polymer backbone, $\left.-\mathrm{CH}-\right)$, $6.5-7.5\left(\mathrm{CONH}_{2}\right.$, $\mathrm{CONH}-$ and aromatic $\mathrm{H}$ ).

A similar procedure was used for making copolymers of AAm and AN with BPA via FRP using AIBN as an initiator and RAFT polymerization with V-70 and AIBN, where CMDT as a chain transfer agent was added together with monomers.

\section{Determination of swelling ratio}

The $2 \mathrm{~mm}$ thick films were prepared by solution casting from $15 \mathrm{wt} \%$ solution in DMSO. The dry films were illuminated with UV light of wavelength $320-390 \mathrm{~nm}$ for $16 \mathrm{~h}$. After UV treatment the films were cut into circles with a diameter of about $20 \mathrm{~mm}$. The films were placed in water at a defined temperature for different time intervals. Thereafter, the samples were taken out and dried carefully using filter paper to remove the unbound solvent. The swelling ratio was calculated using formula (1).

$$
\alpha=\frac{m_{\mathrm{water}}}{m_{\text {polymer }}}=\frac{m_{\text {swollen }}-m_{\mathrm{dry}}}{m_{\mathrm{dry}}}
$$

where $m_{\text {swollen }}$ is the mass of the sample after immersion in water and $m_{\mathrm{dry}}$ is the mass of the original dry sample.

\section{Formation of nanofibers by electrospinning}

The solution for electrospinning was prepared by dissolving $1.0 \mathrm{~g}$ of polymer into the mixture of solvents $(1.0 \mathrm{~g}$ distilled water and $1.0 \mathrm{~g}$ of DMSO). The conventional one needle set-up was used for electrospinning and a high potential voltage of $20 \mathrm{kV}$ was applied on the needle tip. The flow rate was $0.3 \mathrm{~mL} \mathrm{~h}^{-1}$ and the nanofibers were collected on a collector coated with an aluminum foil with a collecting distance of $35 \mathrm{~cm}$. The nanofiber mat was cross-linked by using UV light for $12 \mathrm{~h}$ and then dried in a vacuum oven at $60{ }^{\circ} \mathrm{C}$ for $12 \mathrm{~h}$ to remove the residual solvent.

\section{Results and discussion}

Various amounts of acrylamide (AAm) and acrylonitrile (AN) were polymerized with $2 \mathrm{~mol} \%$ of a polymerizable photo crosslinker 4-acryloyloxybenzophenone (BPA) via RAFT polymerization using AIBN as an initiator and cyanomethyl dodecyl 


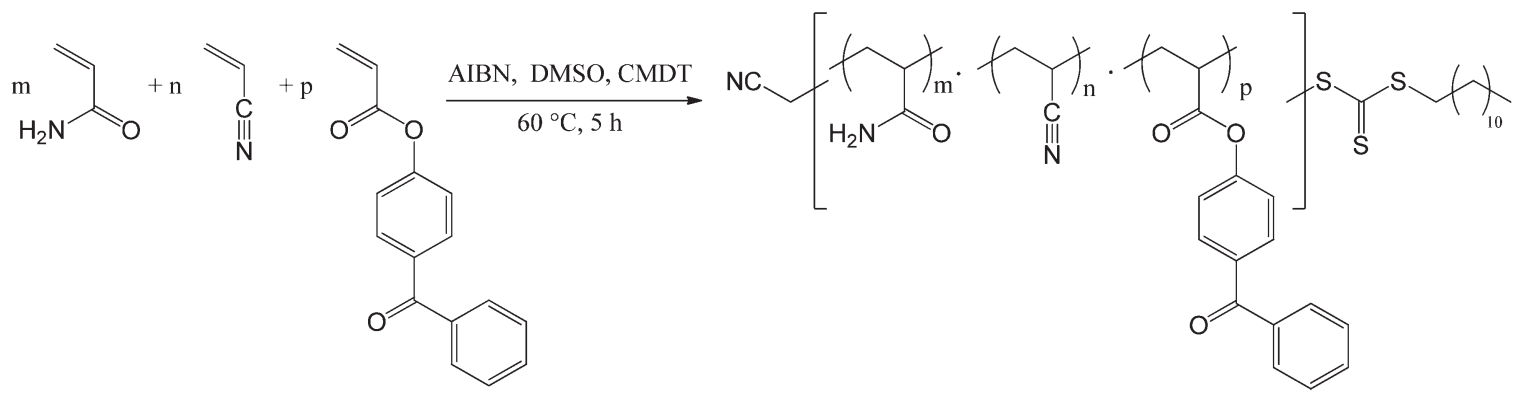

Scheme 1 Synthetic scheme for the formation of a photo cross-linkable UCST-type polymer with 4-acryloyloxybenzophenone (BPA) as the crosslinker by the RAFT method.

Table 1 Free radical and RAFT polymerization of AAm, AN and BPA using AIBN as an initiator and CMDT as the chain transfer agent

\begin{tabular}{|c|c|c|c|c|c|c|}
\hline Entry & $\begin{array}{l}\text { Type of } \\
\text { polymerization }^{a}\end{array}$ & $\begin{array}{l}\text { AAm : AN : BPA } \\
\text { in feed (mol\%) }\end{array}$ & $\begin{array}{l}\text { Conversion } \\
(\%)\end{array}$ & $\begin{array}{l}M_{\mathrm{n}}{ }^{b} \\
(\mathrm{kDa})\end{array}$ & $\mathrm{PDI}^{b}$ & $\begin{array}{l}\text { Cloud point by } \\
\text { cooling }{ }^{c}\left({ }^{\circ} \mathrm{C}\right)\end{array}$ \\
\hline 1 & FRP & $92: 6: 2$ & 62 & 25 & 1.8 & Insoluble \\
\hline 3 & FRP & $96: 2: 2$ & 75 & 26 & 1.6 & Insoluble \\
\hline 4 & FRP & $98: 0: 2$ & 78 & 31.2 & 1.7 & Soluble \\
\hline 5 & RAFT & $83: 15: 2$ & 52 & 17.8 & 1.2 & 48 \\
\hline 6 & RAFT & $88: 10: 2$ & 63 & 21.4 & 1.1 & 38 \\
\hline
\end{tabular}

${ }^{a}$ For free radical polymerization, monomer:AIBN molar ratio was 100:0.5 and for RAFT polymerization monomer:AIBN:CMDT was $100: 0.15: 0.5 .{ }^{b}$ Determined by DMSO GPC using pullulan as the calibration standard. ${ }^{c}$ Turbidity measurements were carried out in water with the sample concentration of $0.2 \mathrm{wt} \%$.

trithiocarbonate (CMDT) as the chain transfer agent (Scheme 1; Table 1).

CMDT was chosen as the RAFT reagent as it was demonstrated to be the most suitable agent in previous studies in terms of control over molar mass, fast rate of reaction and high polymer conversions for polymerization of monomers with primary amide side groups such as $N$-acryloylglycinamide (NAGA) and acrylamide. ${ }^{22,23}$ High molar mass polymers (18 000-23 000 Da) with low molar mass dispersity (1.1-1.2) could be prepared by RAFT polymerization (Table 1). Structural characterization was done using ${ }^{1} \mathrm{H}$ NMR and UV/Vis spectroscopy (Fig. S1 and S2 $\uparrow$ ). The protons from amide and BPA overlapped at 6.5-7.5 ppm in ${ }^{1} \mathrm{H}$ NMR. The existence of benzophenone in the polymer could be proved by UV/Vis spectroscopy by showing the absorption peak of benzophenone at $310 \mathrm{~nm}$ in DMSO.

For turbidity measurements $0.2 \mathrm{wt} \%$ aqueous solutions were used. The cloud points were determined by means of the first derivative of the turbidity curves. Copolymers synthesized by RAFT within a suitable composition range showed UCSTtype sharp phase separation in water. Copolymers with different cloud points ranging from 20 to $48{ }^{\circ} \mathrm{C}$ could be prepared by changing the molar ratio of AAm and AN in the feed (Table 1). The results were similar to the tuning of cloud points of poly(AAm-co-AN) prepared by free radical polymerization (FRP) with a change in the amount of AN in the feed as shown by us previously. ${ }^{23}$ It is worth mentioning that none of the copolymers prepared by conventional FRP using the AIBN initiator at $60{ }^{\circ} \mathrm{C}$ provided thermoresponsive polymers. They were either soluble or insoluble in water at temperatures between 0 and $100{ }^{\circ} \mathrm{C}$ (Table 1). A similar behavior was also observed for AAm copolymers with styrene in which polymers prepared by RAFT were thermoresponsive in comparison with the polymers prepared by free-radical polymerization due to compositional homogeneity. ${ }^{23}$

Further turbidity measurements were performed for different polymer concentrations between 0.05 and $2.0 \mathrm{wt} \%$ (Fig. 1). It was found that in this concentration range the polymer showed a typical UCST-type cloud point dependence on concentration. The cloud point increased with an increase in solution concentration with almost no hysteresis.

The reproducibility of thermoresponsive behavior was checked by carrying out turbidity measurements for many cycles. A shift in the cloud point to a lower temperature with each new cycle was observed as shown in Fig. 2A. Nine consecutive turbidity measurements for a sample (Table 1, entry 6, AAm: AN:BPA $=88: 10: 2)$ in water with the concentration of $0.2 \mathrm{wt} \%$ are shown. The decrease in the cloud point with every new heating-cooling cycle was also observed for copolymers of NAGA and butyl acrylate in our previous study. In contrast, copolymers of AAm and AN (poly(AAm-co-AN)) showed highly stable UCST-type thermoresponsive behaviour for at least 9 cycles without change in cloud points as shown by us previously. ${ }^{19}$ One of the pre- 

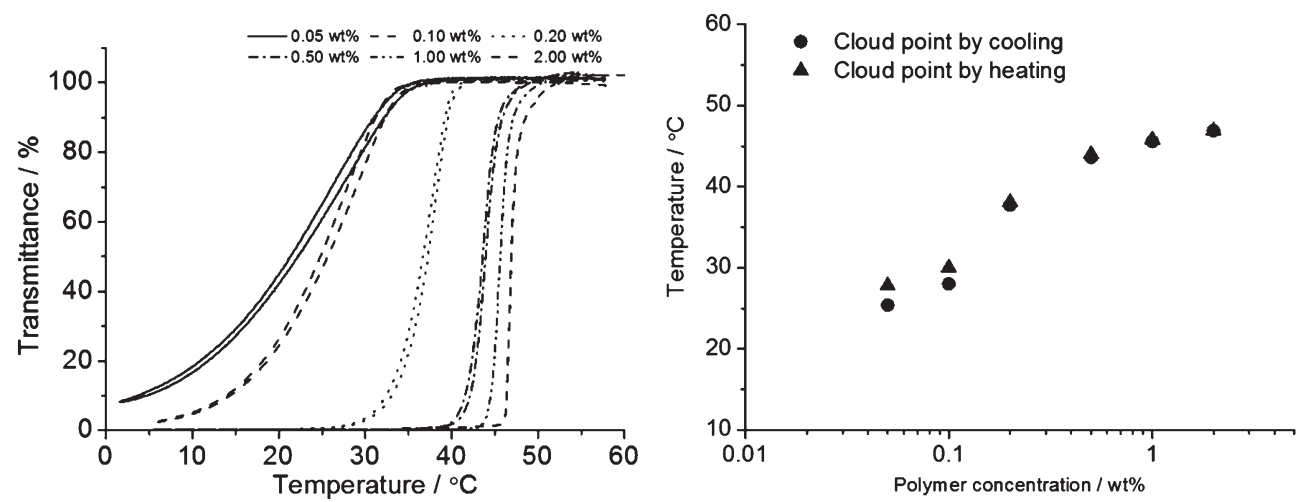

Fig. 1 Turbidity measurements were carried out for different polymer concentrations between 0.05 and 2.0 wt\% (Table 1, entry 6, AAm : AN : BPA = $88: 10: 2, M_{n}=21.4 \mathrm{kDa}$ ). The depicted plots show that the temperature of the phase transition is dependent on the solution concentration and varies between 20 and $50{ }^{\circ} \mathrm{C}$ for the investigated concentration range. Furthermore, it can be seen that the hysteresis is very small and vanishes at higher concentrations.
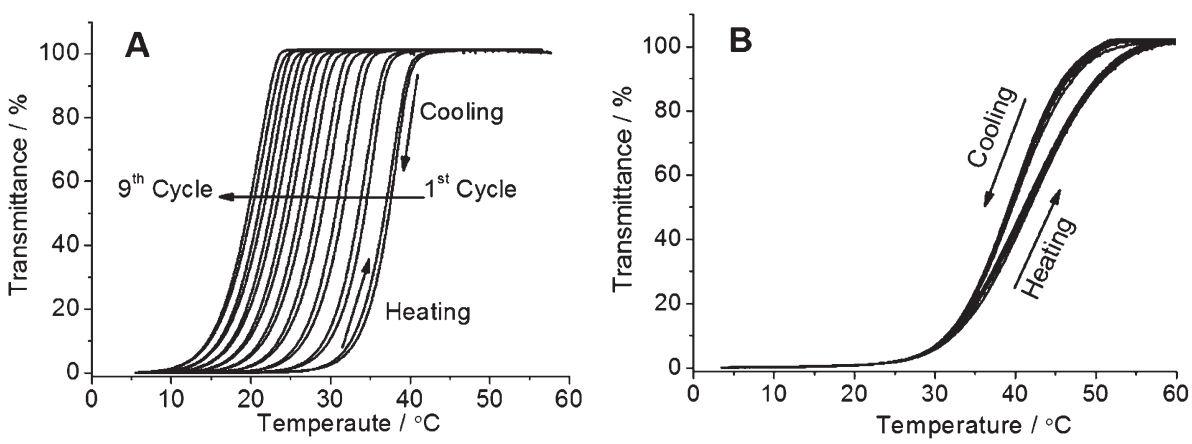

Fig. 2 (A) Nine consecutive turbidity measurements of $0.2 \mathrm{wt} \%$ solution of poly(AAm-AN-BPA) in water (Table 1 entry 6 , AAm : AN : BPA = $88: 10: 2$, $\left.M_{\mathrm{n}}=21.6 \mathrm{kDa}, \mathrm{PDI}=1.1\right)$. (B) Turbidity measurement of the sample poly $(\mathrm{AAm}-\mathrm{AN})$ in water with a concentration of $0.5 \mathrm{wt} \%\left(M_{\mathrm{n}}=21 \mathrm{kDa}, \mathrm{PDI}=1.6\right.$, AN in polymer $=13 \mathrm{~mol} \%$ ). The nine times consecutive measurement overlap, indicating that the polymer is stable against hydrolysis.

vious data was reproduced by making a copolymer of AAm and AN (poly(AAm-co-AN), $M_{\mathrm{n}}=21 \mathrm{kDa}$, PDI $=1.6$, AN in polymer $=13 \mathrm{~mol} \%$ ) and measuring cloud points for 9 heating-cooling cycles as shown in Fig. 2B. The different consecutive measurements overlapped, indicating a stable thermoresponsive behavior and hydrolytic stability of AAm and AN. Therefore, the decrease in the cloud point with each new heating-cooling cycle for the ter-copolymers of AAm, AN and BPA was probably due to the hydrolysis of the photo cross-linker BPA.

To avoid the possible hydrolysis during polymerization and sample preparation, 2,2'-azobis(4-methoxy-2,4-dimethyl valeronitrile) (V-70) as an initiator with low thermal decomposition temperature and $N$-(4-benzoylphenyl)acrylamide (BPAm) as the hydrolytically stable photo cross-linkable monomer were used (Scheme 2). V-70 is a DMSO soluble azo initiator and allows polymerizations at lower temperatures. ${ }^{24,25}$ The terpolymers of AAm, AN and BPAm (AAm : AN : BPAm $88: 10: 2 ; M_{\mathrm{n}}=18000 \mathrm{~g} \mathrm{~mol}^{-1}$ ) prepared by RAFT polymerization using $\mathrm{V}-70$ an initiator showed highly reproducible UCST-type transition in water (Table 2, Fig. 3A). The cloud point did not change for at least 9 cycles thereby implying a highly stable system. Even terpolymers prepared by FRP using V-70 as an initiator at $45{ }^{\circ} \mathrm{C}$ and AIBN at $60{ }^{\circ} \mathrm{C}$ also showed thermoresponsive behavior of UCST-type reproducible for many cycles (Table 2; Fig. S3 $\dagger$ ). This also confirmed the appropriate use of amide based BPAm as the photo cross-linkable monomer in comparison with easily hydrolysable ester based BPA. The photo crosslinkable polymers with UCST-type thermoresponsivity could also be prepared with different cloud points by just changing the amount of AN in the feed (Table 2, entries 2, 4 and 5). The cloud point of $0.1 \mathrm{wt} \%$ polymer solutions increased with a higher amount of AN in the feed: from $30{ }^{\circ} \mathrm{C}(8 \% \mathrm{AN})$ via $40{ }^{\circ} \mathrm{C}(10 \% \mathrm{AN})$ to $52{ }^{\circ} \mathrm{C}(12 \% \mathrm{AN})$. This result agreed with our previous contribution regarding FRP of AAm and AN that polymers with higher hydrophobicity showed a higher cloud point. ${ }^{19}$ The cloud point increased with concentration as shown in Fig. 3B for a terpolymer with AAm:AN:BPAm $90: 8: 2$ (Table 2, entry 4). The cloud point for highly concentrated solution $(10 \mathrm{wt} \%)$ was much higher $\left(85^{\circ} \mathrm{C}\right.$ as observed visually). The measurement of $\%$ transmittance $v s$. temperature was not possible for this sample (10 wt\%) with a high cloud point using an available turbidity meter or UV/Vis photometer in our laboratory. 


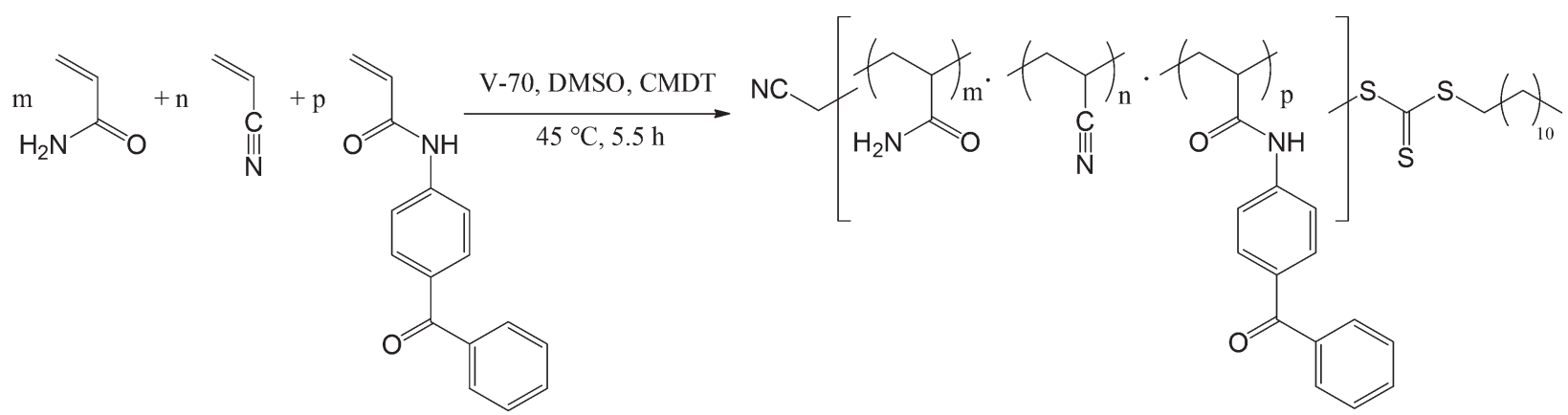

Scheme 2 Synthetic scheme for the formation of a photo cross-linkable UCST-type polymer with N-(4-benzoylphenyl)acrylamide (BPAm) as the cross-linker by the RAFT method.

Table 2 Characterization of terpolymers prepared by FRP and RAFT polymerization of AAm, AN and BPAm in DMSO

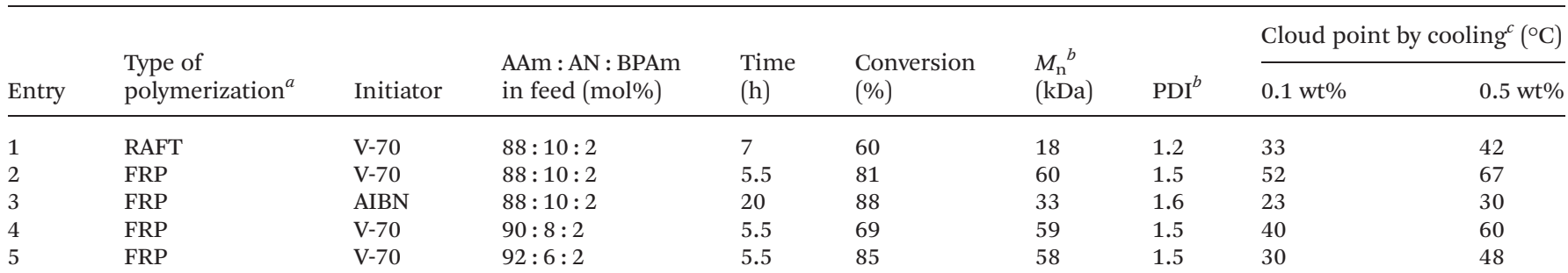

${ }^{a}$ For free radical polymerization, monomer: initiator molar ratio was 100:0.5 and for RAFT polymerization monomer: initiator: CMDT was $100: 0.15: 0.5 .{ }^{b}$ Determined by DMSO GPC using pullulan as the calibration standard. ${ }^{c}$ Turbidity measurements were carried out in water.
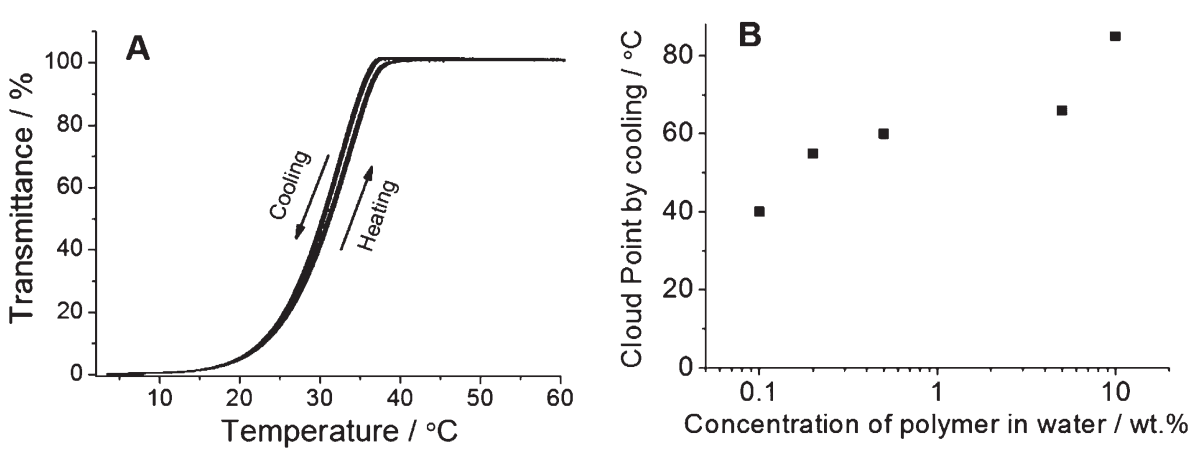

Fig. 3 (A) Nine consecutive measurements of 0.1 wt\% solution of poly(AAm-AN-BPAm) prepared by RAFT (Table 2, entry 1 ) using V-70 as an initiator. The copolymer showed excellent hydrolytic stability and reproducible cloud points with very negligible hysteresis (cloud point on cooling: $32.8^{\circ} \mathrm{C}$; cloud point on heating: $\left.33.5^{\circ} \mathrm{C}\right)$. (B) Cloud point dependence on the concentration of poly(AAm-AN-BPAm) in water by cooling (Table 2 , entry 4 , AAm : AN : BPAm $=90: 8: 2$ ). The cloud point for 10 wt $\%$ was observed visually.

The terpolymer films prepared from DMSO solution were cross-linked by illumination with UV light for $16 \mathrm{~h}$. The illuminated cross-linked films were not soluble in water but showed temperature dependent swelling with a fast equilibration in about 30 minutes. The swelling ratio increased continuously with an increase in temperature showing thermophilic behavior (Fig. 4A). The temperature dependent swelling was reversible with temperature for at least 5 cycles tested in this work (Fig. 4B).

Poly(AAm-AN-BPAm) terpolymers were also used to show the possibility of preparing thermophilic hydrogel fibrous membranes. Such membranes could be highly promising for wound healing and drug release applications in the future. Poly(AAm-AN-BPAm) (AAm:AN : BPAm $=90: 8: 2$ ) with the molecular weight of $59 \mathrm{kDa}$ and polydispersity of 1.5 was chosen for preparing nanofiber mat via solution electrospinning. The electrospinning solution was prepared by dissolving the polymer in a mixture of water and DMSO $(1: 1 \mathrm{wt} \%)$ and provided fibers with the diameter $480 \pm 78 \mathrm{~nm}$. The fibrous mat also showed thermophilic behavior with the change in swelling as observed from changed dimensions of mat with temperature (Fig. 5). The diameter of dry nanofibers also changed from $480 \pm 78 \mathrm{~nm}$ to $880 \pm 91 \mathrm{~nm}$ after placing in water at $20^{\circ} \mathrm{C}$ for $1 \mathrm{~h}$ retaining their fibrous structure (Fig. 6). 

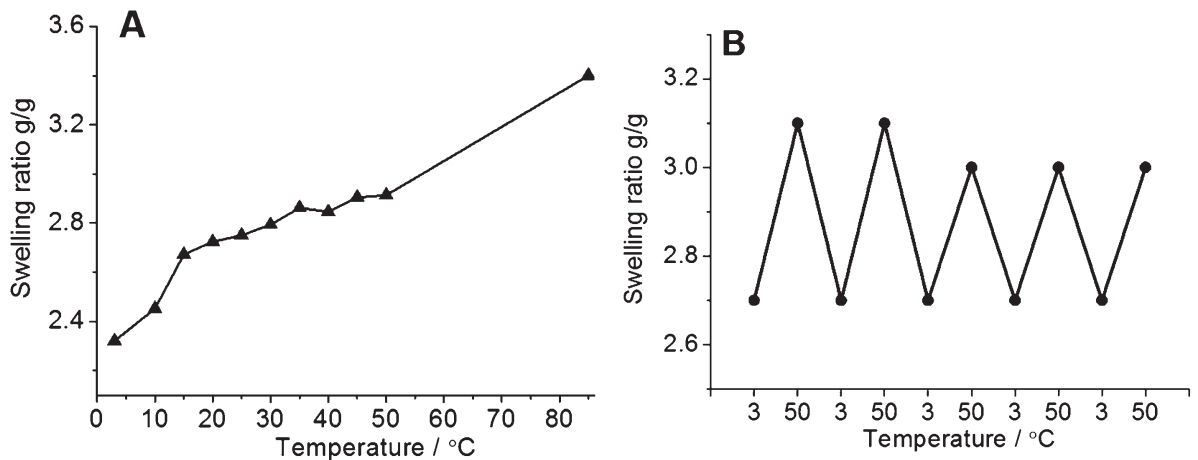

Fig. 4 (A) Temperature dependence of swelling ratio of hydrogels in water prepared by using UV irradiation from the terpolymer DMSO solution (Table 2, entry 4, AAm : AN : BPAm = 90:8:2). The measurements were performed starting from $50{ }^{\circ} \mathrm{C}$ followed by cooling to $3{ }^{\circ} \mathrm{C}$. The swelling ratio data at $85{ }^{\circ} \mathrm{C}$ were obtained by testing an extra sample to avoid the effect of possible hydrolysis of the hydrogel. At each temperature the samples were equilibrated for $30 \mathrm{~min}$. (B) Reversibility of the volume transition of hydrogel in water.

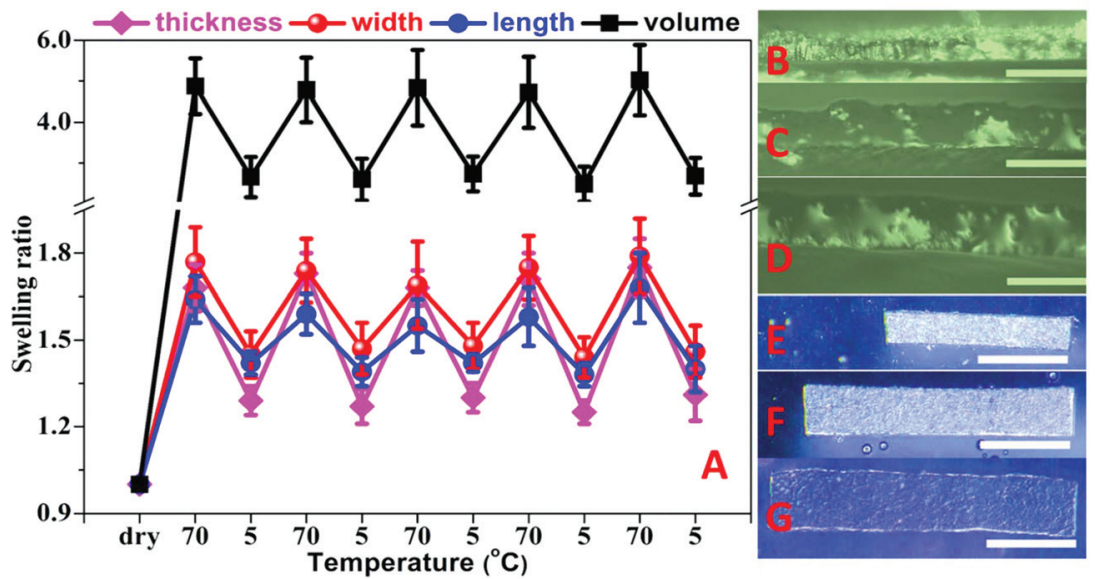

Fig. 5 (A) Temperature dependent swelling behavior (thickness, width, length and volume changes) of electrospun fibrous mat; (B-D) microscopy photos of thickness change of the nanofiber mat in the dry state, the wet state at $5^{\circ} \mathrm{C}$ and $70{ }^{\circ} \mathrm{C}$ respectively; ( $\mathrm{E}-\mathrm{G}$ ) microscopy photos of a small piece of nanofiber mat in the dry state, the wet state at $5^{\circ} \mathrm{C}$ and $70^{\circ} \mathrm{C}$. Scale bar of $(B-D)=100 \mu \mathrm{m}$ and scale bar of $(E-G)=500 \mu \mathrm{m}$.

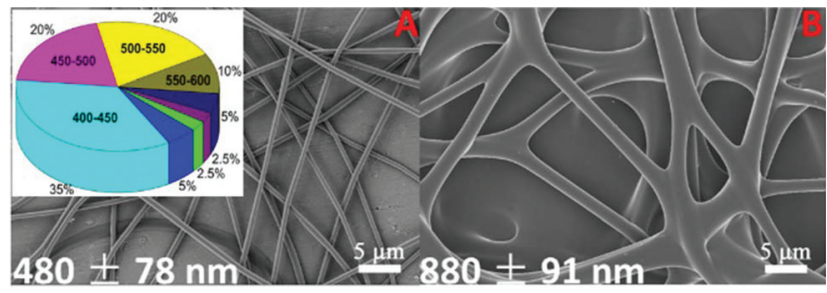

Fig. 6 SEM images of polymer nanofibers in the (A) dried and (B) wet state. Insert: pie chart of the fiber diameter distribution.

The fibrous mat also displayed a temperature dependent reversible change in transparency as shown in Fig. 7.

Finally we demonstrated the fabrication of thermoresponsive self-rolled polymer films with UCST behavior using synthesized polymers. In order to approach this goal, we first explored the possibilities of fabricating microstructures formed by poly(AAm-AN-BPAm) (Table 2, entry 4, AAm : AN : BPAm =

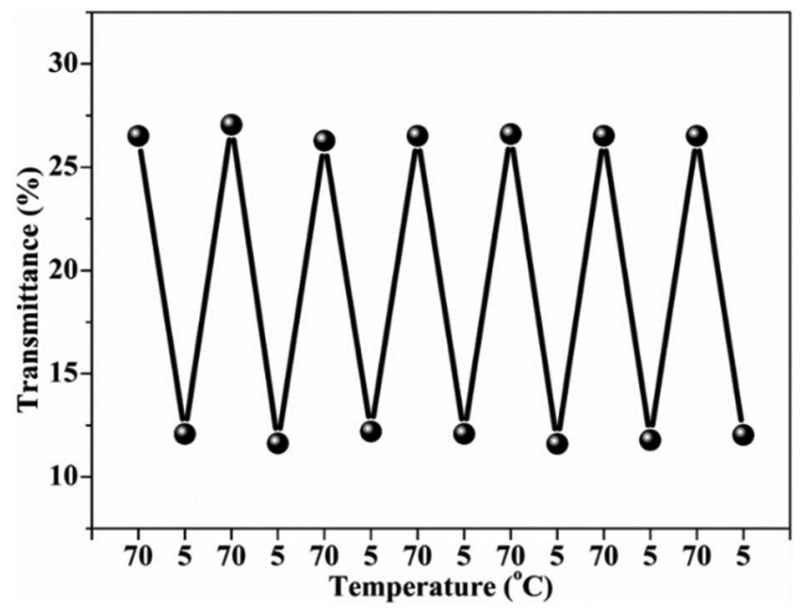

Fig. 7 Temperature dependent transmittance of the polymer fibrous mat in cold water $\left(5^{\circ} \mathrm{C}\right)$ and hot water $\left(70^{\circ} \mathrm{C}\right)$. The thickness of the mat in the dry state is about $40 \mu \mathrm{m}$. 

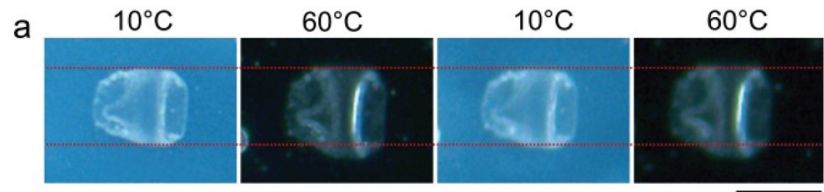

b

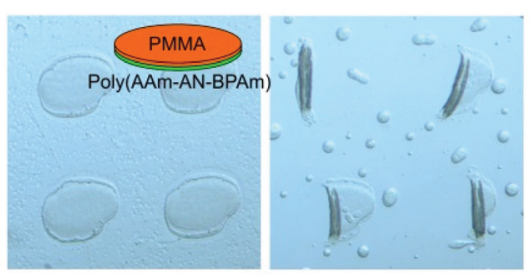

$10^{\circ} \mathrm{C}$
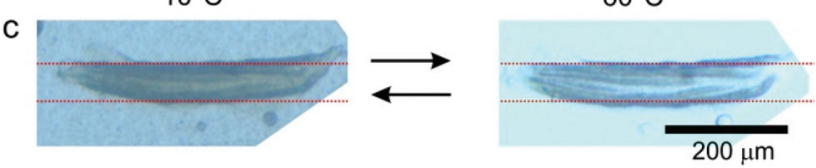

Fig. 8 Actuation behavior of poly(AAm-AN-BPAm)-based photocrosslinked films. (a) Swelling/deswelling of the crosslinked poly(AAmAN-BPAm) film at different temperatures; (b) rolling of a poly(AAmAN-BPAm)/poly(methyl methacrylate) bilayer; (c) actuation behavior of self-rolled poly(AAm-AN-BPAm)/poly(methyl methacrylate) tubes at different temperatures.

$90: 8: 2)$ only. The polymer was positioned on the silicon wafer by dip-coating from its $6 \%$ DMSO solution. The dried film was irradiated through the photomask by using $254 \mathrm{~nm}$ UV light. The formed film was immersed in water and its actuation behavior was investigated by optical microscopy (Fig. 8a). We observed that the non-cross-linked polymer dissolves when the temperature increases above $60{ }^{\circ} \mathrm{C}$. The patches of the crosslinked polymer remain intact on the surface of the wafer. We observed that the size of cross-linked pieces of polymer changes with temperature i.e. size reduces at a low temperate $\left(T=10^{\circ} \mathrm{C}\right)$ and reversibly increases at an elevated temperature $\left(T=60^{\circ} \mathrm{C}\right)$. The change in the size was completely reversible and can be repeated many times. We found that the increase in width and length of the samples is ca. $12-14 \%$. Considering that the hydrogel is isotropic one can assume that the change in the thickness must also be in this range. Thus, the increase in the volume of hydrogel because of swelling can be estimated as $50 \%$ that is larger than in the case of macroscopic pieces (Fig. 4, change in the volume is $c a .15 \%$ ). This could be due to a difference in the cross-linking density.

Next we investigated rolling of poly(AAm-AN-BPAm)-poly(methyl methacrylate) bilayers. The bilayers were prepared as described earlier. ${ }^{26}$ The bilayers are flat and undeformed at low temperature (Fig. 8b, left) because the thermoresponsive polymer is not swollen. Increase in temperature results in swelling of poly(AAm-AN-BPAm) and rolling of the bilayer. As a result poly(AAm-AN-BPAm)-poly(methyl methacrylate) bilayer tubes are formed (Fig. 8b, central and right images). The formed tubes are unable to unroll upon cooling that is commonly observed when the tubes are formed by multiple rolling. On the other hand, cooling results in a slight decrease in the diameter of the tubes (Fig. 8c). The decrease and increase in the diameter of the tubes upon cooling and heating are completely reversible processes and can be repeated many times.

\section{Conclusions}

Photo cross-linkable thermoresponsive polymers showing phase transition of UCST-type in water could be successfully prepared by copolymerization of AAm, AN and BPAm with almost no hysteresis during heating and cooling cycles. The UCST-behavior was highly stable and reproducible for at least 9 cycles tested in the present work. The cloud point could be easily tuned by changing the feed composition. The polymers could be easily processed to films and fibers. The UV crosslinking provided the corresponding thermophilic hydrogels in the form of film and fibrous membranes showing temperature dependent positive volume transitions that was unitized for the design of microactuators. The hydrogels could be highly promising in future for use in wound dressing, drug release applications, microactuators and biofabrication.

\section{Acknowledgements}

Deutsche Forschungsgemeinschaft (DFG) is kindly acknowledged for the financial support.

\section{Notes and references}

1 J. P. Chen and A. S. Huffman, Biomaterials, 1990, 11, 631.

2 A. Kondo, H. Kamura and K. Higashitani, Biotechnol. Bioeng., 1994, 44, 1.

3 Y. Oni and W. O. Soboyejo, Mater. Sci. Eng., C, 2012, 32, 24.

4 W. L. J. Hinrichs, N. M. E. Schuurmans-Nieuwenbroek, P. van de Wetering and W. E. Hennink, J. Controlled Release, 1999, 60, 249.

5 N. Nath and A. Chilkoti, Adv. Mater., 2002, 14, 1243.

6 E. Gil and S. Hudson, Prog. Polym. Sci., 2004, 29, 1173.

7 J. Seuring and S. Agarwal, Macromol. Rapid Commun., 2012, 33, 1898.

8 J. Seuring and S. Agarwal, ACS Macro Lett., 2013, 2, 597.

9 F. Liu, J. Seuring and S. Agarwal, Macromol. Chem. Phys., 2014, 215, 1466.

10 E. Mah and R. Ghosh, Processes, 2013, 1, 238.

11 G. S. Georgiev, Z. P. Mincheva and V. T. Georgieva, Macromol. Symp., 2001, 164, 301.

12 J. Ning, K. Kubota, G. Li and K. Haraguchi, React. Funct. Polym., 2013, 73, 969.

13 E. A. Bekturov and L. A. Bimend, in Adv. Polym. Sci., Springer, Berlin, Heidelberg, 1980, vol. 41, pp. 99-147.

14 H. Katono, A. Maruyama, K. Sanui, N. Ogata, T. Okano and Y. Sakurai, J. Controlled Release, 1991, 16, 215. 
15 N. Shimada, S. Kidoaki and A. Maruyama, RSC Adv., 2014, 4, 52346 .

16 N. Shimada, H. Ino, K. Maie, M. Nakayama, A. Kano and A. Maruyama, Biomacromolecules, 2011, 12, 3418.

17 N. Shimada, M. Nakayama, A. Kano and A. Maruyama, Biomacromolecules, 2013, 14, 1452.

18 J. Seuring, F. M. Bayer, K. Huber and S. Agarwal, Macromolecules, 2012, 45, 374.

19 J. Seuring and S. Agarwal, Macromolecules, 2012, 45, 3910.

20 G. Stoychev, N. Puretskiy and L. Ionov, Soft Matter, 2011, 7, 3277.
21 J.-D. Cho, S.-G. Kim and J.-W. Hong, J. Appl. Polym. Sci., 2006, 99, 1446.

22 F. Liu, J. Seuring and S. Agarwal, J. Polym. Sci., Part A: Polym. Chem., 2012, 50, 4920.

23 B. A. Pineda-Contreras, F. Liu and S. Agarwal, J. Polym. Sci., Part A: Polym. Chem., 2014, 52, 1878.

24 J. Brandrup, E. H. Immergut and E. A. Grulke, Polymer Handbook, John Wiley, New York, 1998.

25 R. Bryaskova, C. Detrembleur, A. Debuigne and R. Jérôme, Macromolecules, 2006, 39, 8263.

26 S. Zakharchenko, N. Puretskiy, G. Stoychev, M. Stamm and L. Ionov, Soft Matter, 2010, 6, 2633. 